\title{
AVALIAÇÃO DO USO E OCUPAÇÃO NA CABECEIRA DO RIO PIRAPOZINHO (SP)
}

Ana Paula de Costa1', Lucas Prado Osco², Rodrigo Coladello ${ }^{2}$, Marcos Norberto Boin ${ }^{1,2}$.

Universidade do Oeste Paulista - UNOESTE. ${ }^{1}$ Curso de Engenharia Ambiental e Sanitária; ${ }^{2}$ Mestrado em Meio Ambiente e Desenvolvimento Regional, Presidente Prudente - SP. E-mail: costalima.paulaana@gmail.com

\section{RESUMO}

O presente trabalho tem por finalidade apresentar o levantamento cartográfico e analítico referente às condições de uso e ocupação na área abarcada pela bacia hidrográfica do rio Pirapozinho, mais precisamente em seu alto curso (cabeceira), na qual se encontram presentes a malha urbana e o aterro municipal de resíduos sólidos. A carta final foi gerada pelo software de geoprocessamento ArcGIS 10.1, vetorizada a partir de fotografias aéreas que compreendiam a região de estudo. A partir de então, trabalhos de campo foram realizados com o intuito de comprovar a veracidade das informações levantadas no mapeamento. $\mathrm{O}$ artigo, portanto, atribui seu enfoque as capacidades intrínsecas do meio físico, destacando os componentes naturais, bem como suas fragilidades, contribuindo para a confecção de um diagnóstico ambiental à área de estudo.

Palavras-chave: Degradação Ambiental. Recursos Hídricos. Bacia do Rio Pirapozinho.

\section{EVALUATION OF USE AND OCCUPATION ON THE HEADWATER OF RIVER PIRAPOZINHO (SP)}

\begin{abstract}
This paper aims to present the cartographic and analytical survey concerning the conditions for the use and occupation in the field covered by the watershed of the river Pirapozinho, more precisely in its upper course (headwaters) area, which concentrates the urban area and the municipal landfill of solid waste. The final map was generated by the software ArcGIS 10.1, upon aerial photographs that comprised the study region. Since then, field work was conducted in order to prove the veracity of the information gathered in the mapping. Therefore, the article attributes his approach on the intrinsic capabilities of the physical environment, highlighting the natural components as well as their weaknesses, contributing to the confection of an environmental assessment for the studied area.
\end{abstract}

Keywords: Environmental Degradation. Water Resources. Basin of River Pirapozinho. 


\section{INTRODUÇÃO}

Em concordância com Garcez (1967), a definição de bacia hidrográfica fundamenta-se no conjunto de áreas ou espaço territorial que apresente caimento superficial direcionado para uma seção transversal - medida através de uma projeção horizontal - determinante de um curso d'água ou canal fluvial. A terminologia bacia hidrográfica, ainda, pode abarcar uma série de diferentes denominações, tais como: bacia de captação; bacia imbrífera; bacia coletora e; bacia de drenagem superficial. Deste modo, a bacia hidrográfica compreende a delimitação de uma área específica, na qual possui dinâmica ambiental exclusiva, incorporando todas as características naturais da região. Segundo Lima (1986), as condições geomorfológicas, geológicas, pedológicas e climáticas, associadas à cobertura vegetacional, estabelecem uma série de influências no comportamento hidrológico das bacias hidrográficas. Neste sentido, evidencia-se, portanto, um conjunto de ações que desempenham funções na gênese das condições ambientais dentro de uma bacia hidrográfica.

Quando se adota o conceito de bacia hidrográfica para a conservação de recursos naturais, torna-se possível avaliar - em áreas delimitadas cartograficamente -, sua produtividade biológica e potencial de desenvolvimento, o que possibilita melhor aproveitamento dos recursos presentes, com a menor degradação ambiental possível, por meio de mecanismos de gerenciamento ambiental adequado (SCHIAVETTI, 2002). Vale mencionar que o avanço científico, voltado para práticas de manejo e gestão desses territórios, demonstra a importância da presença de vegetações ciliares locadas no entorno das margens do canal fluvial, bem como à suas nascentes e áreas úmidas, com o intuito de garantir a qualidade e proteção dos recursos hídricos (ZAKIA, 1998).

A poluição dos recursos hídricos, sejam superficiais ou subterrâneos, diminui cada vez mais o percentual de água disponível e de boa qualidade para o consumo humano, induzindo a consequências sociais, econômicas e ambientais, comprometendo todo o desenvolvimento da sociedade, a saúde humana e o equilíbrio do ecossistema local. Os principais poluentes dos recursos hídricos são os efluentes domésticos e industriais lançados sem o devido tratamento nos corpos d'água, chuvas com impurezas da atmosfera e do solo, o lixo urbano lançado nas ruas (ou depositados em aterros), pesticidas e fertilizantes utilizados na agricultura, detergentes de diversos tipos utilizados para remoção de gorduras e graxas, além de sedimentos carreados pela 
chuva ou vento provenientes de áreas erodidas. (LIBÂNIO, 2010).

De acordo com Christofoletti (1974), os acontecimentos decorrentes em uma bacia de drenagem repercutem - direta ou indiretamente - no corpo d'água. As condições climáticas, somadas a cobertura vegetal e a litologia da área são responsáveis por controlar o tipo de carga dendrítica fornecida aos rios. Desta maneira, o estudo e a análise dos cursos d'água devem ser realizados em razão da perspectiva do sistema hidrográfico. Assim, o planejamento e gerenciamento de bacias hidrográficas necessitam incorporar não somente os recursos hídricos, mas também todos os recursos ambientais presentes no espaço avaliado, utilizando uma abordagem de integração dos aspectos ambientais, sociais, econômicos e políticos, preocupando-se mais com o primeiro e incluindo a finalidade da qualidade ambiental no uso de seus recursos, visando aumentar a produtividade em conjunto com a diminuição dos impactos e riscos ambientais na bacia de drenagem. (SCHIAVETTI, 2002).

\section{Localização da Área de Estudo}

O município de Pirapozinho (Figura 1) encontra-se inserido na UGRHI (Unidade de Gerenciamento de Recursos Hídricos) - 22, localizando-se ao extremo oeste do estado de São Paulo, abrangendo, conforme o IBGE (2010), 480,795 km² de área, abrigando uma população total de 24.718 habitantes. Em razão das características potencialmente poluidoras da área - presença da malha urbana, galeria do esgoto, efluente de frigorífico e do aterro municipal de resíduos sólidos -, o presente estudo atribuiu seu enfoque à cabeceira do rio Pirapozinho, bacia hidrográfica, esta, situada ao norte do município, entre os territórios pertencentes à Alvares Machado e Pirapozinho.

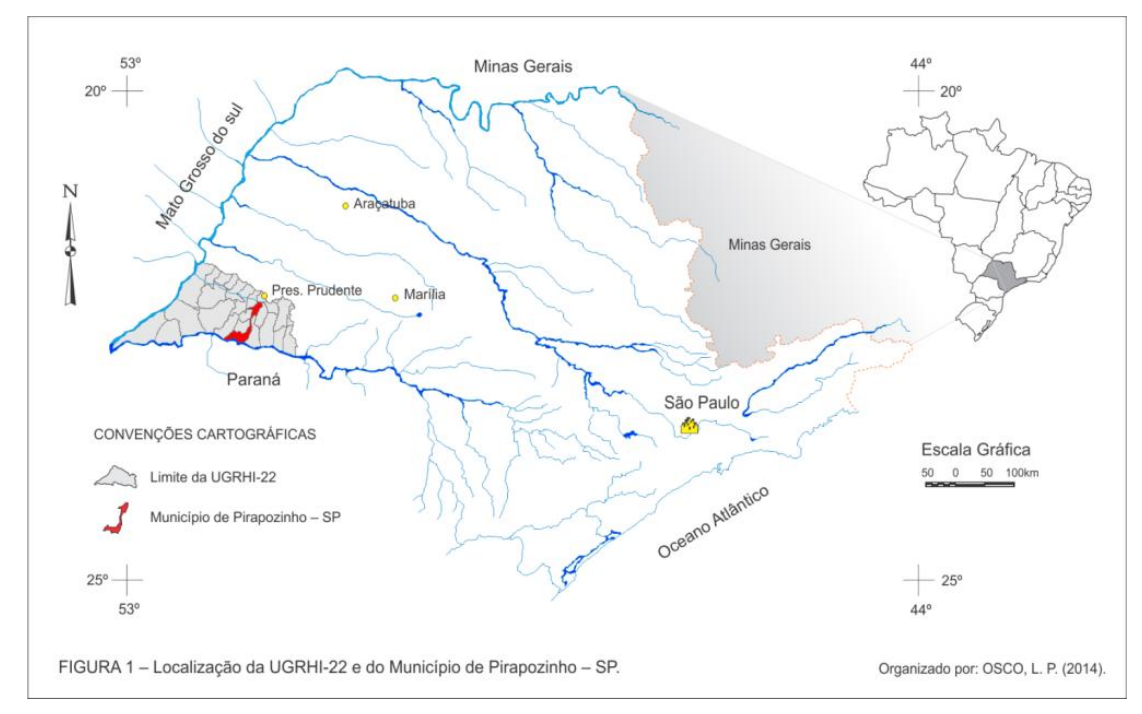

Figura 1. Localização da UGRHI-22 e do Município de Pirapozinho - SP 


\section{METODOLOGIA}

Em um primeiro momento, a revisão bibliográfica embasou-se no levantamento de conceitos chaves ligados à interpretação do meio físico, às características naturais da área e às implicações que a prática e manejo inadequados de bacias hidrográficas resultam. Em seguida, utilizando técnicas de sensoriamento remoto sobre ortofotografias, por meio do software ArcGIS 10.1, interpretaram-se as principais características do meio físico e antrópico no ambiente de estudo. Estas informações possibilitaram a análise ocupacional da área na bacia, além da avaliação de suas implicações na contaminação dos recursos hídricos superficiais e subterrâneos locais. Por último, com o intuito de corroborar a veracidade dessas informações, realizaram-se pesquisas "in loco", observando as condições naturais da cabeceira do rio Pirapozinho.

\section{RESULTADOS E DISCUSSÃO}

O levantamento cartográfico associado ao trabalho de campo efetuado tornou possível a confecção de uma carta final (Figura 2), destacando as áreas de uso e cobertura do solo. Para tanto, constatou-se: a presença significativa da malha urbana acima do divisor de águas; o aterro municipal de resíduos sólidos, locado próximo à rodovia; a vasta extensão de áreas de pastagem, marcadas por poucas áreas de agricultura e; as rodovias, estradas e vicinais utilizadas no local. Em relação aos recursos naturais, delimitou-se: as áreas de matas ciliares e de matas arbóreas; a ocorrência de lençóis suspensos em meia encosta e de lençóis em fundo de vale; os espelhos d'água encontrados na bacia; a rede de drenagem e; as planícies aluviais ao longo do canal fluvial (Quadro 1).

A análise aprofundada dos elementos averiguados em campo sugere o risco ou a potencialidade de contaminação incidente na cabeceira do rio Pirapozinho, de modo a comprometer em muito com as condições ambientais locais, principalmente no que diz respeito aos recursos hídricos encontrados na bacia. Para tanto, deve-se discorrer sobre os fatores naturais que determinam certa vulnerabilidade para a área (substancialmente o solo, o relevo e os recursos hídricos), relacionando-os as formas de cobertura e uso na bacia.

Embora não destacados no mapa apresentado, os tipos de solos presentes na bacia representam condições substanciais para o risco de contaminação dos recursos hídricos. Salienta-se que a área é inteiramente composta por argissolo vermelho-amarelo eutrófico (EMBRAPA, 1999), com pequenas porções de neossolos litólicos e solos hidromórficos. Os argissolos, comumente encontrados por toda a extensão territorial da bacia, oferece maior restrição à 
contaminação subterrânea justamente por

minerais

de

argila.

constituírem-se de maiores quantidades de

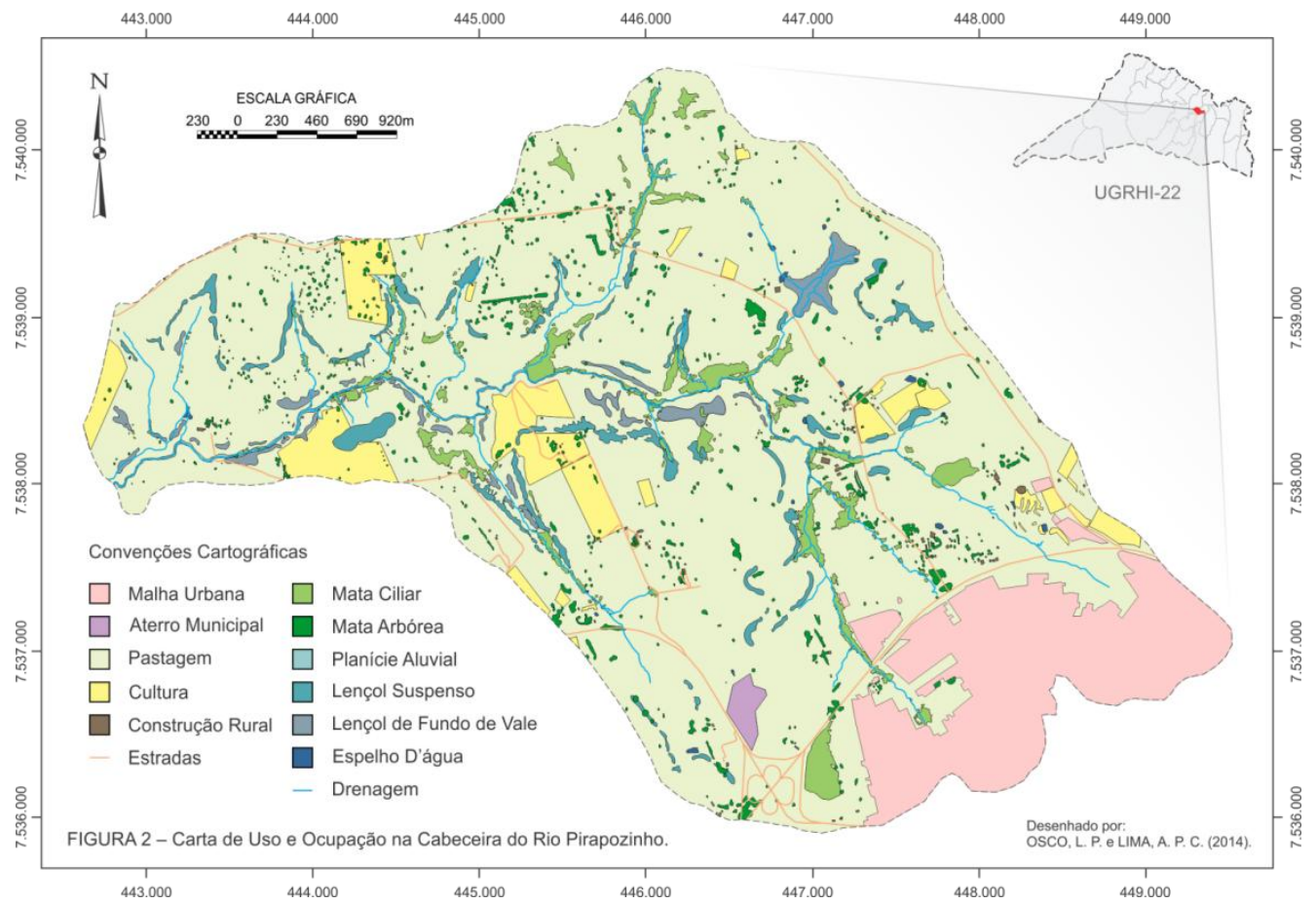

Figura 2. Carta de Uso e Ocupação na Cabeceira do Rio Pirapozinho.

Quadro 1. Extensão territorial das áreas mapeadas.

\begin{tabular}{|c|c|c|c|c|c|}
\hline $\begin{array}{c}\text { Malha } \\
\text { Urbana }\end{array}$ & $\begin{array}{c}\text { Aterro } \\
\text { Municipal }\end{array}$ & Pastagem & Cultura & $\begin{array}{c}\text { Construção } \\
\text { Rural }\end{array}$ & $\begin{array}{c}\text { Mata } \\
\text { Ciliar }\end{array}$ \\
\hline 179,92 ha & 5,81 ha & 1144,54 ha & 96,18 ha & 2,76 ha & 56,47 ha \\
\hline $\begin{array}{c}\text { Mata } \\
\text { Arbórea }\end{array}$ & $\begin{array}{c}\text { Planície } \\
\text { Aluvial }\end{array}$ & $\begin{array}{c}\text { Lençol } \\
\text { Suspenso }\end{array}$ & $\begin{array}{c}\text { Lençol de Fundo de } \\
\text { Vale }\end{array}$ & Espelho D'água & Área Total \\
\hline 32,10 ha & 7,19 ha & 45,34 ha & 23,98 ha & 2,28 ha & $\begin{array}{c}1596,57 \\
\text { ha }\end{array}$ \\
\hline
\end{tabular}

Não obstante, representa um

problema em razão da baixa profundidade, pois em setores de maior declividade, ou até potencial de infiltração e, portanto, mesmo na área escavada para o aterro contaminação. !shape.area!/10000

Ainda referente aos solos, no tange municipal, é perceptível a presença do material rochoso, sugerindo cortes abruptos na camada litológica (Figura 3). Isto, conforme Moreira et al. (2007), representa um alto risco, pois em zonas de fissuras geológicas, o contato com esta camada, principalmente pelos resíduos sólidos e em específico ao neossolo litólico, este se encontra relacionado à declividade acentuada do relevo. Quando há um corte ou quebra no relevo de forma abrupta, é comum a exposição da camada rochosa (Figura 3), que ao passar por fases de intemperismo, produz a desagregação de 
partículas que formam o neossolo. Os solos hidromórficos (ou gleissolos), por sua vez, restringem-se próximos às áreas úmidas, principalmente em planícies de inundação do canal fluvial. Estes solos são susceptíveis e facilmente erodidos, oferecendo alta drenabilidade, conferindo-lhes um risco extremamente elevado quando em contato com as atividades poluidoras.

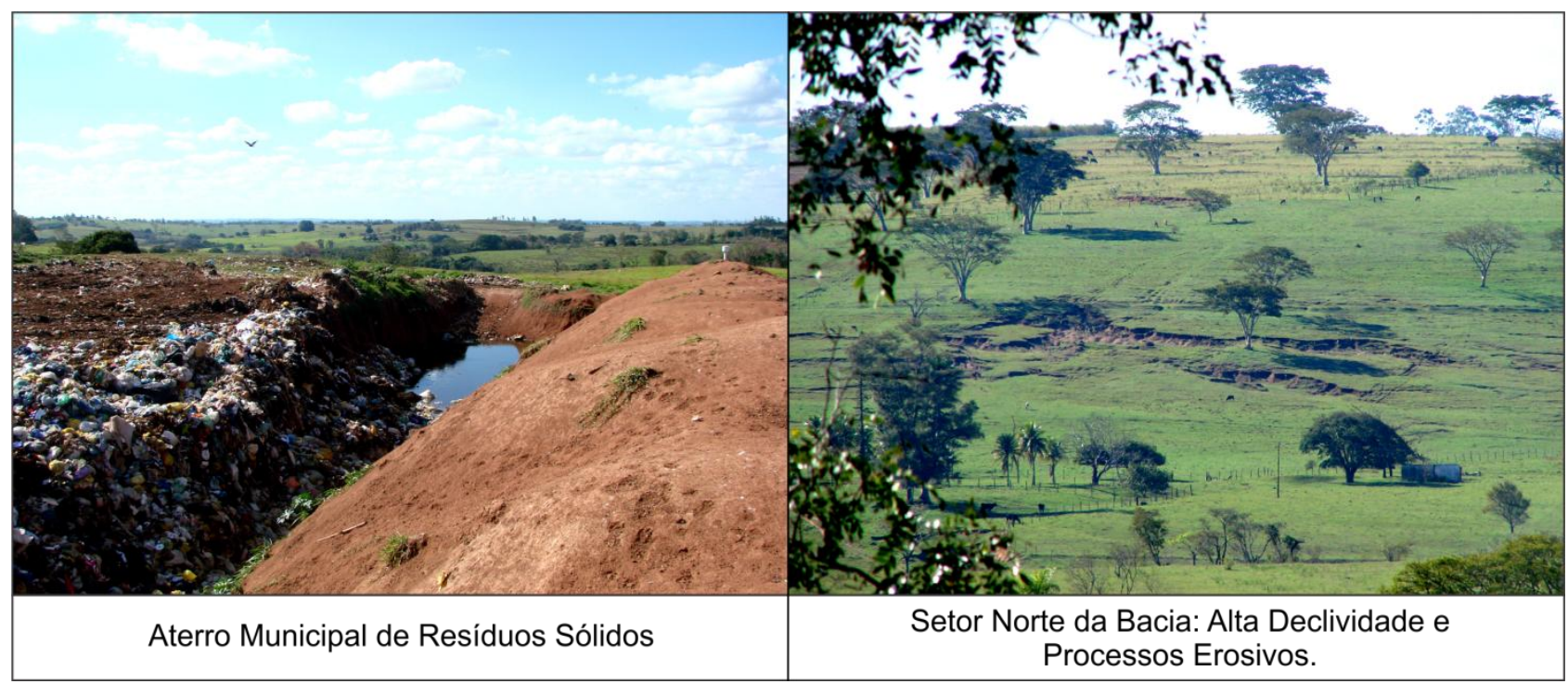

Figura 3. Aterro Municipal e Processos Erosivos na Cabeceira do Rio Pirapozinho.

Em relação à distribuição topográfica e hidrográfica na área, a bacia possui um relevo fortemente ondulado e bem acentuado em vertentes próximas a calha principal do rio Pirapozinho. Em áreas marcadas por alta declividade ocorre, conforme relatado, a exposição do maciço rochoso, assim como o afloramento de lençóis suspensos em meia encosta. Estes lençóis decorrem em razão da discrepância entre as litofácies geológicas da Formação Adamantina (ALMEIDA et al., 1981) que ocupam a área na bacia, ora constituindo-se por camadas arenosas, ora argilosas, conferindo esta capacidade de permeabilidade e retenção dos líquidos nas encostas, reveladas pelo declive acentuado na forma do modelado.

A área é demarcada por colinas médias, consistindo-se em interflúvios sem orientação preferencial, com drenagem padrão dendrítica e de média a alta densidade (IPT, 1981). Esta drenagem, por sua vez, é alimentada por diversos corpos d'água presentes na bacia. Os lençóis suspensos, assim como os lençóis de fundo de vale e as nascentes, são responsáveis por abastecer continuamente o rio principal. Já as planícies aluviais ocorrem próximas às áreas de entalhamento dos cursos d'água maiores, recobertas, que são por sedimentos fluviais em razão do acréscimo de 
sedimentos transportados para os fundos dos vales pelo volume do rio durante os períodos de maior índice pluviométrico.

Deste modo, subentende-se que os elementos supracitados conferem a cabeceira do rio Pirapozinho condições de vulnerabilidade. Este ambiente, embora se encontre atualmente antropizado, conserva algumas de suas características. A bacia é composta primordialmente por áreas de pastagem, possuindo poucas matas ciliares, o que favorece o assoreamento dos córregos em razão da fragilidade natural do solo presente. Deve-se, entretanto, destacar os processos advindos do espaço urbano (calha de esgoto, efluente do frigorífico, dentre outros) que contribui para uma provável poluição dos mananciais (Figura 4). O principal, entretanto, ainda é o aterro municipal situado próximo à rodovia.

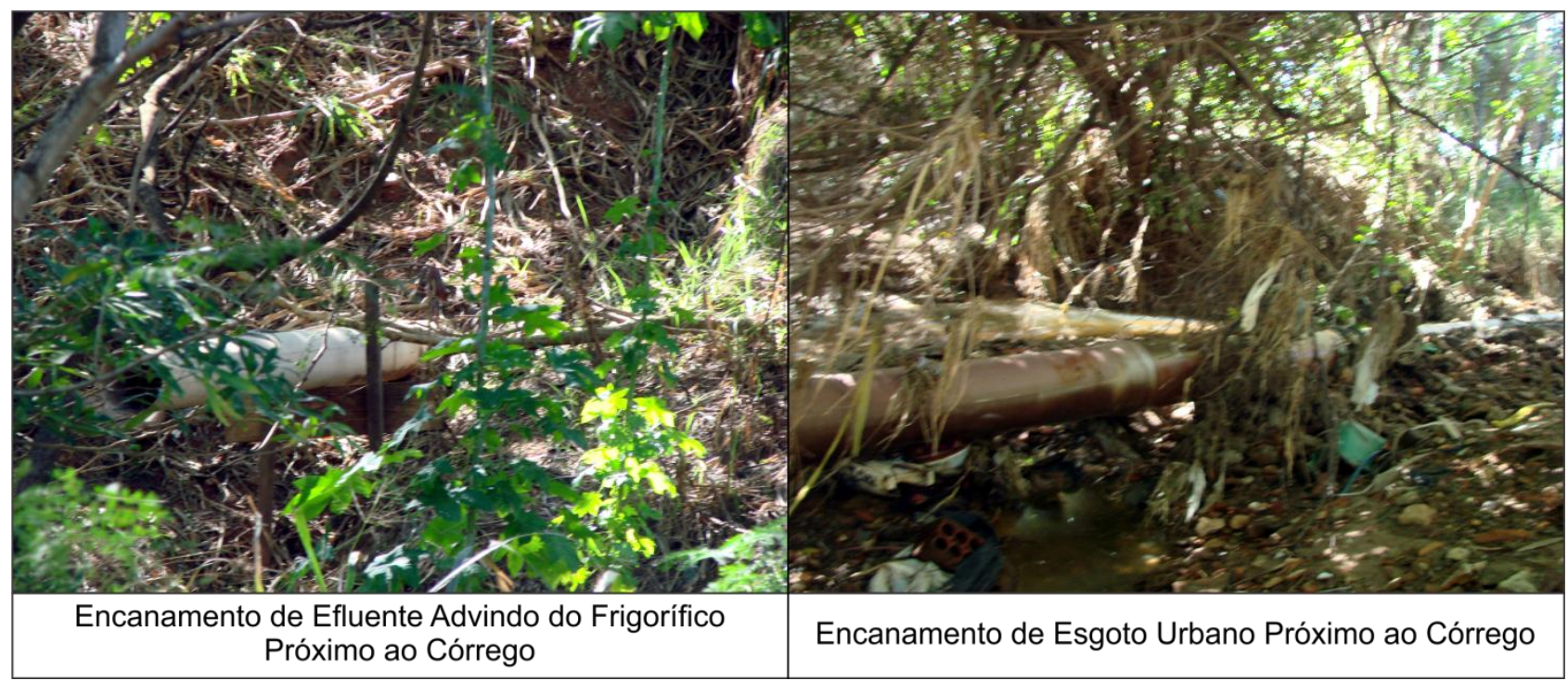

Figura 4. Frigorífico e Esgoto Urbano na Cabeceira do Rio Pirapozinho.

Para tanto, quantificar os valores dessas substâncias, de modo a determinar a potencialidade de degradação dos recursos naturais, sugere estudos de cunho específico, onde se fazem necessários a coleta e posterior análise de amostras de água em pontos estratégicos dos corpos d'água desta bacia. Não obstante, o estudo voltado para as práticas de uso e ocupação territorial da área permite, em um primeiro momento, diagnosticar os setores de maior vulnerabilidade ou fragilidade natural. A partir de então, torna-se possível diagnosticar o meio físico, com o intuito de auxiliar pesquisas futuras que contribuam para uma melhor gestão da bacia hidrográfica estudada.

\section{CONCLUSÃO}

Em suma, as características naturais do ambiente analisado evidenciam o manejo 
inadequado da bacia em enfoque. Dentre os usos elencados neste artigo, destaca-se aquele relacionado ao aterro de resíduos sólidos, que ao encontrar-se sob um solo pouco espesso, e, consequentemente sobre - maciço rochoso, apresenta maior fragilidade e capacidade de retenção do contaminante oriundo do chorume produzido. Além dos usos referentes aos resíduos sólidos, o frigorífico e o esgoto urbano, outra condição negativa para a área se faz justamente na escassez de matas ciliares ao entorno dos córregos e áreas úmidas, contribuindo para o aumento de processos erosivos como ravinas, voçorocas, e do assoreamento do canal fluvial. Estas condições podem ser revertidas, entretanto torna-se necessário a aplicação de práticas conservacionistas na área, promovidas pelo gerenciamento apropriado da bacia hidrográfica.

\section{REFERÊNCIAS}

ALMEIDA, M. A. de et al. Considerações sobre a estratigrafia do Grupo Bauru na região do pontal do Paranapanema no Estado de São Paulo. InSIMPÓSIO REGIONAL DE REOLOGIA. 3., 1981, Curitiba. Anais... , Curitiba: SBG - SP, 1981.

CHRISTOFOLETTI, A. Geomorfologia. São Paulo: Edgard Blücher, . 1974.149p.

\section{EMBRAPA. Mapa Pedológico do Estado de} São Paulo: Legenda expandida / Oliveira, J. B. et al. Campinas, Instituto Agronômico; Rio de Janeiro: Embrapa solos, 1999.
GARCEZ, L. N. Hidrologia. Sao Paulo: EDUSP Edgard Blucher, 1967. 249 p.

IPT - Instituto de Pesquisas Tecnológicas do Estado de São Paulo. Mapa Geomorfológico do Estado de São Paulo, 1:1.000.000. São Paulo, IPT, 1981. v. 2.

LIBÂNIO, M. Fundamentos de qualidade e tratamento de água.3.ed. Campinas:Átomo, 2010.

LIMA, W.P. Princípios de hidrologia florestal para o manejo de bacias hidrográficas. São Paulo: Escola Superior de Agricultura "Luiz de Queiroz",1986. ", 242p.

MOREIRA, M. A. A.; LORANDI, R.; MORAES, M. E. B. de. Caracterização de áreas preferenciais para a instalação de aterros sanitários no município de Descalvado (SP), na escala 1:50.000. Revista Brasileira de Cartografia, n. 60, n. 02, 2008.

SCHIAVETTI, A.; CAMARGO, A. F. M. Conceitos de bacias hidrográficas: teorias e aplicações. Ilhéus, Bahia: Editus, 2002.

ZAKIA, M. J. B. Identificação e caracterização da zona ripária em uma microbacia experimental: Implicação no Manejo de Bacias Hidrográficas e na recomposição de florestas. 1998. Tese (Doutorado em Ciências da Engenharia Ambiental) - Escola de Engenharia de São Carlos, Universidade de São Paulo, São Carlos, SP.

Recebido para publicação em 11/08/2014 Revisado em 03/09/2014 Aceito em 08/09/2014 